DOI: $10.12731 / 2306-1561-2013-4-14$

\title{
PROCESS MODEL OF TRANSPORTATION MIX CONCRETE
}

\section{Bashmakov I.A., Ostroukh A.V.}

\section{Abstract}

The paper proposes a process model of transportation mix concrete, which is a structured description of a means of transportation technology mix concrete road at the level of the production process. Range of activities related to the transportation of concrete mixtures is presented in the form of hierarchically nested processes that are coordinated on the basis of general systems theory. The model is described in a strict sequence: process chain $\rightarrow$ process step $\rightarrow$ process link, and all built technological chains consist of indivisible units.

Keywords: road transport; process chain; the transport process; transportation of concrete mixes.

\section{УДК 656.025}

\section{ПРОЦЕССНАЯ МОДЕЛЬ ТЕХНОЛОГИИ ТРАНСПОРТИРОВКИ БЕТОННЫХ СМЕСЕЙ АВТОМОБИЛЬНЫМ ТРАНСПОРТОМ}

Башмаков И.А., Остроух А.В.

\section{Аннотация}

В статье предложена прочессная модель, представляющая собой средство структурированного описания технологии транспортировки бетонных смесей автомобильным транспортом на уровне производственных прочессов. Комплекс работ, связанных с транспортировкой бетонных смесей представлен в виде иерархически вложенных прочессов, координируемых на основании общей теории систем. Модель описывается в строгой последовательности: технологическая цепь $\rightarrow$ технологический этап $\rightarrow$ технологическое звено (кортеж), а все построенные технологические цепи состоят из неделимых звеньев.

Ключевые слова: автомобильный транспорт, технологическая цеепь, транспортный процесс, транспортировка бетонных смесей.

\section{Введение}

В настоящее время, несмотря на повсеместное применение технологии монолитного строительства, существует крайне мало методических разработок, направленных на совершенствование транспортного процесса доставки бетонных смесей. 
Значительный эффект может быть получен в результате представления процессов производства строительных материалов, в том числе и бетонных смесей, как основной составляющей монолитного железобетонного строительства, их транспортирования на объектах и организации работ в комплексе - в виде единой цепи взаимосвязанных подсистем [4 - 11], а также при разработке новых методов и моделей автотранспортного обслуживания, снижающих производственные риски.

Анализ существующей технологии транспортирования бетонных смесей автомобильным транспортом

Существующая технология транспортирования бетонных смесей автомобильным транспортом, применяемая в Российской Федерации показана на рисунке 1.

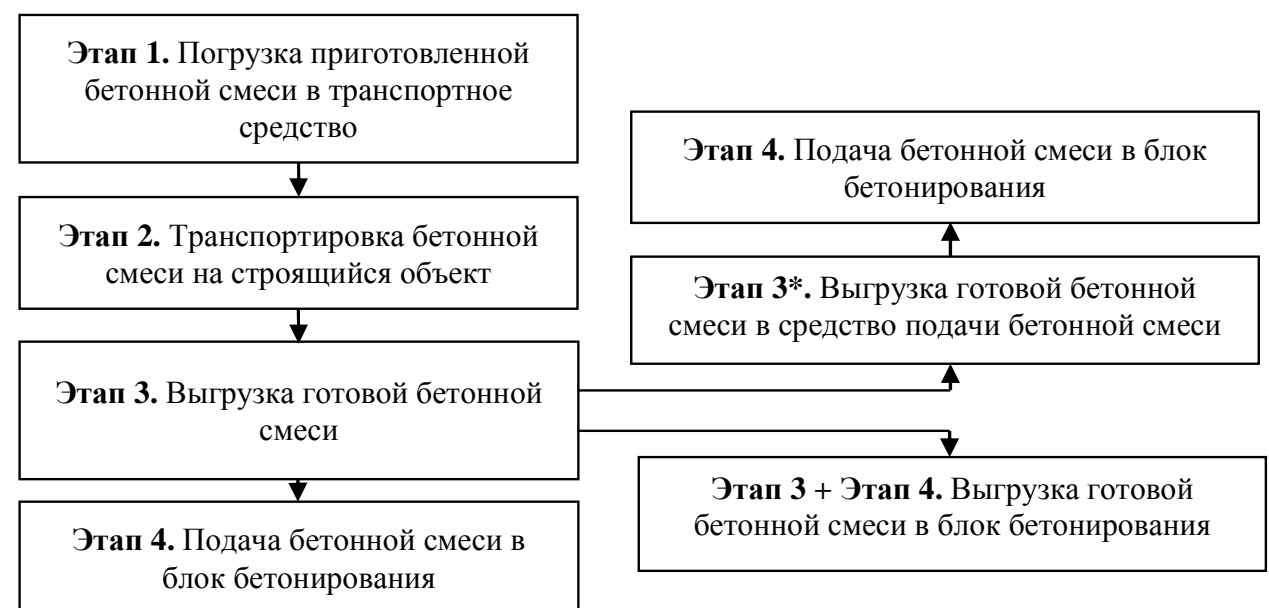

\section{Рисунок 1 - Технологическая схема процесса транспортирования готовой бетонной смеси}

Проведенный анализ показал, что на сегодняшний день, существуют следующие условия, при которых возможна рационализация рассматриваемой технологии:

1) научно-обоснованная рационализация технологии транспортирования бетонных смесей должна иметь предварительно определенную основную идею роста организованности самой технологии или её процессов;

2) рационализация рассматриваемой технологии должна базироваться только на чётком, разработанном плане действий, т.к. транспортирование бетонных смесей представляет собой сложную последовательность взаимосвязанных процессов и процедур;

3) обеспечение приемлемой целостности, непрерывности и равномерности реализации технологии транспортирования бетонных смесей автомобильным транспортом;

4) абсолютно все изменения, вносимые при рационализации технологии транспортирования бетонных смесей, должны быть согласованы, в противном случае это приведет к снижению организованности всей технологии и сбоям в её работе; 
МАТЕРИАЛЫ ІХ МЕЖДУНАРОДНОЙ ЗАОЧНОЙ НАУЧНО-ПРАКТИЧЕСКОЙ КОНФЕРЕНЦИИ МОЛОДЫХ УЧЕНЫХ «ТЕОРИЯ И ПРАКТИКА ПРИМЕНЕНИЯ ИНФОРМАЦИОННЫХ ТЕХНОЛОГИЙ В ПРОМЫШЛЕННОСТИ И НА ТРАНСПОРТЕ», г. Москва, 12 ноября 2013 г.

5) рационализация технологии должна учитывать оптимальную концентрацию каждого из процессов транспортирования бетонных смесей на определенной сфере деятельности.

6) обеспечение оптимального распределения задач, функций, информационных потоков и связи между процессами во всей технологии транспортирования бетонных смесей автомобильным транспортом.

В ходе проведенного анализа выявлены недостатки, имеющиеся в сфере транспортирования бетонных смесей автомобильным транспортом в РФ:

- отсутствие четкого и структурированного описания самой технологии транспортирования бетонных смесей в изученной автором тематической литературе и источниках;

- неполное и не конкретизированное описание аспектов организации подготовительных операций к погрузке бетонной смеси на подвижной состав и выгрузке его в пункте доставки в изученной автором тематической литературе и источниках;

- недостаточная степень рационализации рассматриваемой технологии транспортирования бетонных смесей автомобильным транспортом для её использования на современных предприятиях, в условиях неопределенности, многокритериальности и производственных рисков.

Исходя из выше изложенного, автор считает необходимым создать модели, методы новую систему организации и управления единого процесса «производствотранспортировка-потребление» автотранспортного обслуживания строительного производства в виде взаимосвязанного комплекса задач производства, транспортирования и использования бетонных смесей, материалов и строительных изделий на объектах строительства, учитывающую производственные риски.

Модель технологии транспортирования бетонных смесей автомобильным транспортом

Технологию транспортирования бетонных смесей автомобильным транспортом предлагается представить в виде иерархически вложенных процессов производится с помощью метода кортежей $[1-3,5]$. Упорядоченное множество фаз в модели первичного процесса организации действий по изменению состояний предмета труда в технологии есть кортеж (звено), фазы которого имеют прямое, т.е. неразрывное отношение друг к другу (рисунок 2). Этот процесс не подлежит дальнейшей декомпозиции и представляет собой первичное звено любой работы в технологии транспортирования бетонной смеси автомобильным транспортом. Каждая фаза в кортеже занимает строго определенное место с жестко детерминированными межфазовыми связями в виде не нарушаемых взаимных обязательств. 


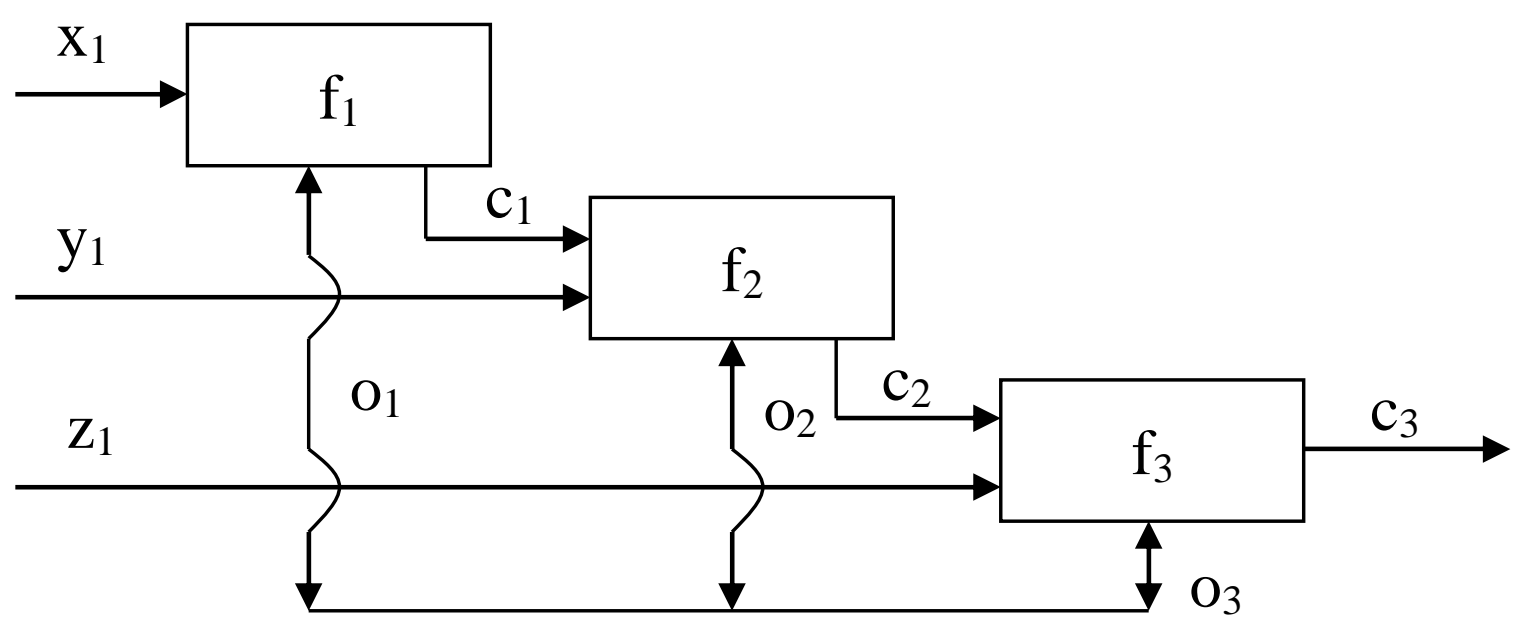

Рисунок 2 - Процессная модель кортежа

Здесь $\mathrm{f}_{1,2,3}$ - порядковый номер фазы кортежа; $\mathrm{c}_{1,2,3}$ - порядковое обозначение связи фаз кортежа; о1,2,3 - обратная связь между фазами кортежа; $\mathrm{x}_{1}, \mathrm{y}_{1}, \mathrm{z}_{1}$ - фазы процесса транспортирования бетонной смеси, например: $\mathrm{x}_{1}$ - отправление загруженного транспортного средства (ТC) с бетоносмесительного завода, у1 следование ТС к строящемуся объекту, $\mathrm{z}_{1}$ - прибытие ТС на строящийся объект.

Далее предложена методика организации технологической цепи «производствотранспортировка-потребление», обеспечивающая согласованное функционирование всех звеньев, при применении которой процесс формирования кортежей и множества соответствий между элементами системы множеств идет до момента преобразования предмета труда в продукт труда или в предмет потребления [1 - 11]. Модель кортежей формируется до тех пор, пока все операции, необходимые для транспортирования бетонных смесей с растворобетонного узла в блок бетонирования не будут структурированы.

Особенность центрального множества в данной модели, как совокупности процессов, определяется его взаимосвязью с множеством согласованных кортежей (рисунок 3), которые отражают всю рассматриваемую технологию.

Здесь звенья отражают конкретное содержание этапов технологии транспортирования бетонной смеси автомобильным транспортом:

- Звено 3 - этап погрузки бетонной смеси в транспортное средство;

- Звено 4 - транспортирование бетонной смеси на строящийся объект;

- Звено 5 - выгрузка бетонной смеси на строящемся объекте.

Данная ациклическая сеть, а это фактически есть семантическая сеть, использующая интерпретацию отношений узлов графа как «часть - целое», отражает содержание технологического звена цепи кортежей, описывающих технологию транспортирования бетонных смесей автомобильным транспортом. 


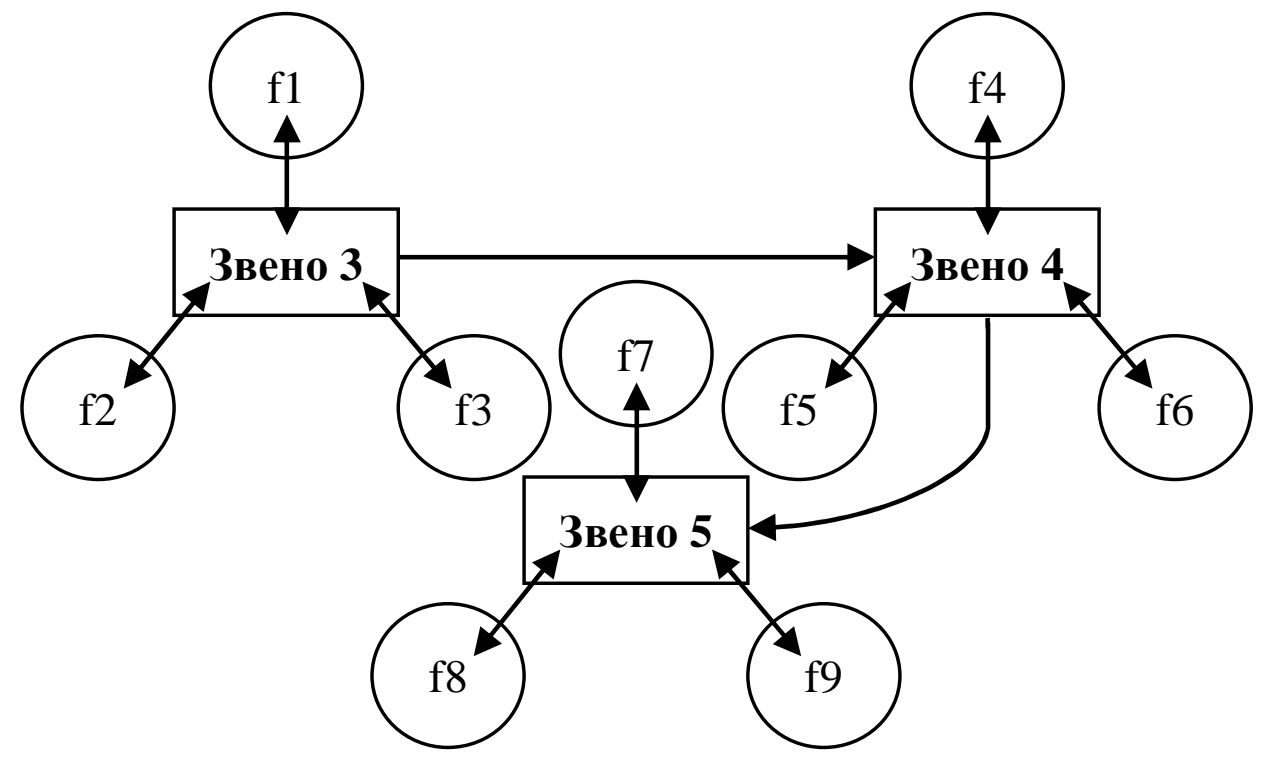

\section{Рисунок 3 - Взаимосвязь кортежей}

Декомпозиция объекта исследования на функциональные подсистемы осуществляется с использованием элементарной функциональной модели процесса (рисунок 4). Она представляет собой минимальную комбинацию основных элементов процессной модели кортежа подробным образом описывающих вышеуказанную технологию.

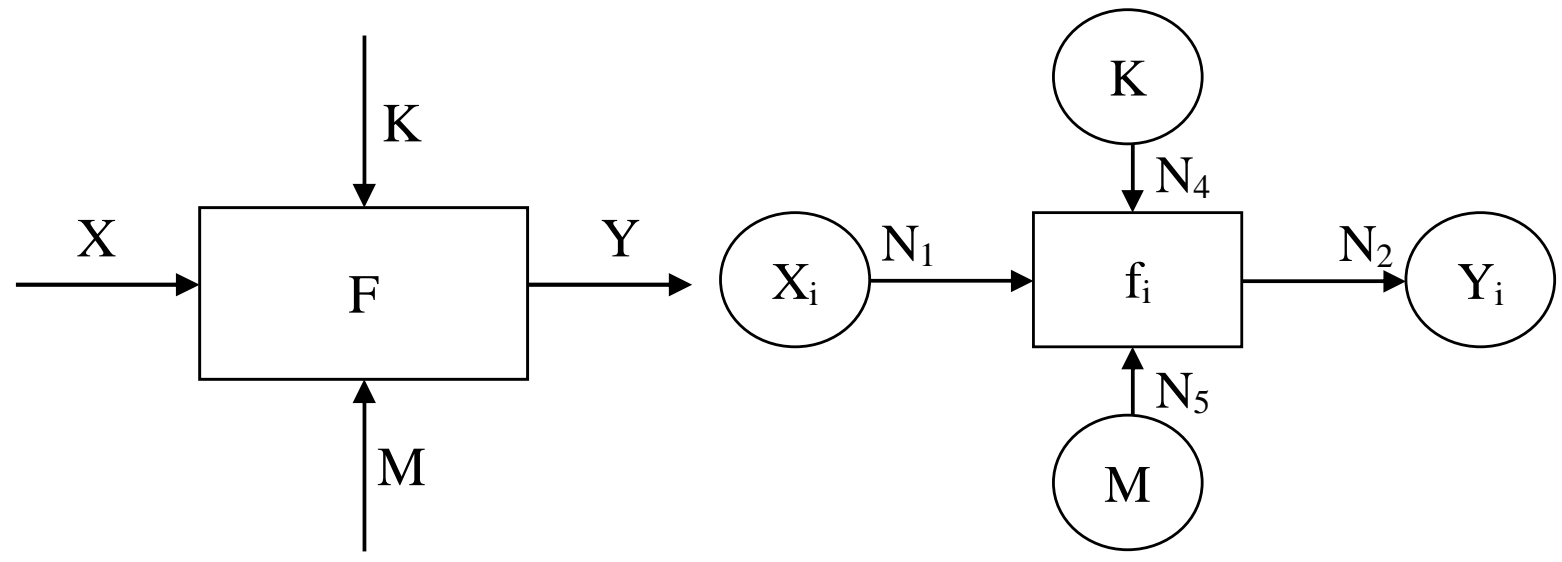

Рисунок 4 - Элементарная функциональная модель процесса

Принципы параметрической оптимизации подсистем и методики выбора их параметров в условиях многокритериальности, неопределенности и производственных рисков таковы: 1) при отношении «один ко многим»: $\mathrm{N}_{1}=\left(\mathrm{X}_{\mathrm{i}}, \mathrm{f}_{\mathrm{i}}\right)$ - элемент «вход»; $\mathrm{N}_{2}=$ $\left(\mathrm{f}_{\mathrm{i}}, \mathrm{Y}_{\mathrm{i}}\right)$ - элемент «выход»; $\mathrm{N}_{4}=\left(\mathrm{K}, \mathrm{f}_{\mathrm{i}}\right)$ - элемент «контроль»; $\mathrm{N}_{5}=\left(\mathrm{M}, \mathrm{f}_{\mathrm{i}}\right)$ - элемент «механизм»; 2) при отношении «многие ко многим»: $\mathrm{N}_{3}=\left(\mathrm{X}_{\mathrm{i}}, \mathrm{Y}_{\mathrm{i}}\right)$ - элемент «действие».

Здесь $\mathrm{X}_{\mathrm{i}}$ - множество накапливаемых предметов труда (связанных с технологией транспортирования бетонных смесей), использованных в качестве элемента «вход» (накопление); $\mathrm{Y}_{\mathrm{i}}$ - множество преобразуемых предметов труда (также связанных с технологией транспортирования бетонных смесей), использованных в качестве 
элемента «выход» (преобразование); $\mathrm{f}_{\mathrm{i}}$ - операция, используемая в качестве элемента «действие» (перемещение); K - множество информационных объектов, используемых в качестве элемента «контроль»; М - множество элементов транспортных структур, использованных в качестве элемента «механизм перемещения предмета труда».

\section{Заключение}

Таким образом, проанализирована существующая технология транспортировки бетонных смесей автомобильным транспортом, включая организацию подготовительных операций к погрузке бетонной смеси на подвижной состав и разгрузке его в пункте доставки, с целью последующей ее рационализации.

Осуществлена общесистемная проработка, позволяющая представить комплекс работ в виде иерархически вложенных процессов, координируемых на основании общей теории систем.

\section{Список информационных источников}

[1] Башмаков И.А., Покровский А.К. Математические модели в риск-менеджменте предприятий транспорта. Грузовое и пассажирское автохозяйство. 2010. № 7. С. 30-33.

[2] Башмаков И.А., Покровский А.К. О надежности и рисках в автотранспортных предприятиях. Грузовое и пассажирское автохозяйство. 2011. № 9. С. 66-69.

[3] Башмаков И.А., Покровский А.К., Комаров А.А. Риски производственных процессов. Транспорт: наука, техника, управление. 2012. № 1. С. 65-67.

[4] Кузнецов И.А. Особенности реализации автоматизированной информационноаналитической системы центра планирования перевозок строительных грузов / И.А. Кузнецов, А.В. Остроух // Вестник МАДИ(ГТУ). - 2008. - Вып. 1(12). - С. $92-$ 96.

[5] Куфтинова Н.Г. Процессно-ориентированный подход к автоматизации планирования и управления транспортировкой продукции предприятий промышленности / А.В. Остроух, Н.Г. Куфтинова // Вестник МАДИ - 2010. - Вып. 4(23). - С. 62-66.

[6] Николаев А.Б. Информационные технологии в менеджменте и транспортной логистике: учебное пособие / А.Б. Николаев, А.В. Остроух. - Saint-Louis, MO, USA: Publishing House Science and Innovation Center, 2013. - 254 c. - ISBN 978-0615-67110-9.

[7] Остроух А.В. Автоматизация распределения транспортных средств и техники по объектам строительства с учетом организационных и технических факторов / А.В. Остроух, Н.Е.Суркова // Приборы и системы. Управление, контроль, диагностика. - М.: «Научтехлитиздат», 2004. - №12. - С. 6-9.

[8] Остроух А.В. Автоматизация и моделирование работы предприятий по строительству промышленных объектов: дис. ... д-ра техн. наук: 05.13.06: защищена 07.04.09: утв. 19.06.09. - М., 2009. - 357 с. 
[9] Остроух А.В. Автоматизация и моделирование работы предприятий по строительству промышленных объектов: автореф. дис. ... д-ра техн. наук: 05.13.06. - М., 2009. - 43 c.

[10] Остроух, А.В. Информационные технологии в научной и производственной деятельности / [ред. А.В. Остроух] - М: ООО "Техполиграфцентр", 2011. - 240 с. ISBN 978-5-94385-056-1.

[11] Ostroukh A.V., Kuftinova N.G. Automation of Planning and Management of the Transportation of Production for Food Processing Industry Enterprises. Automatic Control and Computer Sciences. 2012. Vol. 46. No. 1. pp. $41-48$. 